\title{
Cerveja artesanal e desenvolvimento regional em Santa Catarina (Brasil) $^{1}$
}

\author{
Valdinho Pellin ${ }^{1}$ e Oklinger Mantovaneli $\mathrm{Jr}^{2}$
}

1 Graduado em Economia. Mestre e Doutorando do Programa de Pós Graduação em Desenvolvimento Regional na Fundação Universidade Regional de Blumenau, Brasil. E-mail: prof.pellin@tpa.com.br

2 Doutor em Sociologia pela UNESP. Professor do Programa de Pós-Graduação em Desenvolvimento Regional da Universidade Regional de Blumenau, Brasil. E-mail: oklingerfurb@gmail.com

RESUM 0: Discussões relacionadas ao fortalecimento do desenvolvimento regional tem estimulado um debate em relação a contribuições que Indicações Geográficas (IGs) podem oferecer ao desenvolvimento. IGs se constituem em elemento de identificação de produtos ou serviços com seus territórios e podem oferecer contribuições importantes para o desenvolvimento regional, agregando valor aos produtos, facilitando o acesso a novos mercados e valorizando tradições locais. Este artigo procura discutir a importância da cerveja artesanal no contexto do desenvolvimento regional em Santa Catarina. Para tanto explora como objetivos específicos: (i) caracterizar as discussões que estão ocorrendo em torno do reconhecimento da IG para chope e cerveja artesanal na região de Blumenau (SC); (ii) identificar contribuições e desafios para o Desenvolvimento Regional de um possível reconhecimento da IG; e (iii) caracterizar limites e potencialidades sinalizados pela iniciativa em curso. M etodologicamente trata-se de pesquisa analítica e descritiva baseada em estudo de caso de natureza exploratória. Como instrumento de coleta de dados se realizou entrevistas semiestruturadas com gestores de micro cervejarias artesanais da região e atores públicos e privados envolvidos diretamente nas discussões. Além destas fontes primárias o estudo fundamentou-se em fontes consubstanciadas pelos documentos produzidos nas reuniões de trabalho realizadas até o presente. Os principais resultados de análise destacam que um possível reconhecimento da IG poderia contribuir para o fortalecimento do setor, aumentando a competitividade, além de fortalecer a atividade turística na região. Entretanto para isso, alguns conflitos, surgidos no âmbito das discussões, precisam ser assumidos, superados ou mitigados.

Palavras Chaves: Cerveja Artesanal, Desenvolvimento Regional, Indicação Geográfica, Santa Catarina.

\section{Craft beer and regional development in Santa Catarina (Brazil)}

ABSTRACT: Discussions related to strengthening regional development has spurred a debate regarding contributions Geographical Indications (GIs) can offer to development. Gls constitute product identification element or services with their territories and can provide important contributions to regional development, adding value to products, facilitating access to new markets and valuing local traditions. This article discusses the importance of craft beer in the context of regional development in Santa Catarina. For that explores how specific objectives: (i) to characterize the discussions that are taking place around the recognition of Gls for draft beer and craft beer in the region of Blumenau (SC); (ii) identify contributions and challenges for the Regional Development of a

10 artigo se desdobra de reflexões ocorridas durante elaboração de tese do primeiro autor sob orientação do segundo autor. 
possible recognition of Gls; and (iii) to characterize boundaries and flagged potential for ongoing initiative. Methodologically it is analytical and descriptive research based on case study of exploratory nature. As data collection instrument was conducted semistructured interviews with managers of micro craft breweries in the area and public and private actors directly involved in the discussions. In addition to these primary sources the study was based on documentary sources substantiated by the documents produced in the working meetings held to date. The main results of the analysis highlight that a possible recognition of Gls could contribute to the strengthening of the sector, increasing competitiveness, and strengthen tourism in the region. However for this, some conflicts that arose in the discussions, need to be overcome or mitigated.

Keywords: Craft Beer, Regional Development, Geographical Indication. Santa Catarina.

\section{INTRODUÇÃO}

Discussões relacionadas ao fortalecimento do desenvolvimento regional tem estimulado um debate em relação a contribuições que produtos tradicionais poderiam oferecer ao desenvolvimento. Trata-se de considerar especificidades locais nas discussões sobre o desenvolvimento regional e na elaboração de estratégias e políticas públicas direcionadas para estimular esse desenvolvimento.

Neste contexto ganha força discussões relacionadas às Indicações Geográficas (IGs) que se constituem em elemento de identificação de produtos ou serviços com seus territórios. Conferem contribuições importantes para o desenvolvimento territorial, sustentável ou não, agregam valor aos produtos e facilitam o acesso a novos mercados. Representam também valorização de tradições locais associadas ao fortalecimento de uma identidade cultural própria.

Há consenso entre pesquisadores que em função de suas características, principalmente a miscigenação de sua cultura, o Brasil possui grande potencial para reconhecimento de produtos com IG. Este potencial pode ser verificado também em Santa Catariana e, particularmente no M édio Vale do Itajaí, onde vários produtos se destacam, entre eles o chope e a cerveja artesanal ${ }^{2}$.

A produção de chope e cerveja artesanal tem se popularizado no Brasil e atualmente há vários polos de produção, inclusive em regiões com pouca tradição no segmento, como as regiões norte e nordeste. Esta popularização da cultura cervejeira tem estimulado o consumo e o surgimento de micro cervejarias, fortalecendo toda cadeia produtiva do setor e estimulando também atividades complementares como 0 turismo cervejeiro.

Em 2010 se iniciaram as discussões relacionadas a possibilidade de solicitar o reconhecimento da IG para chope e cerveja artesanal produzida na região de Blumenau (SC). As discussões surgiram no âmbito do Núcleo de Inovação Tecnológica da Universidade Regional de Blumenau (NIT/FURB) e, conforme avançavam, contaram com o envolvimento de entidades públicas e privadas além de micro cervejarias da região.

2 Atualmente se discute na região de Blumenau (SC) a possibilidade de solicitar também o reconhecimento de IG para cristais e queijo Korkäse.

PRACS: Revista Eletrônica de Humanidades do Curso de Ciências Sociais da UNIFAP 
Este artigo resgata a gênese do empreendimento, efetuando uma análise a partir da experiência de discussão para a obtenção do reconhecimento da IG para chope e cerveja artesanal da região de Blumenau (SC). Para tanto, explora como objetivos específicos: (i) caracterizar as discussões que estão ocorrendo em torno do reconhecimento da IG para chope e cerveja artesanal na da região de Blumenau (SC); (ii) identificar contribuições e desafios para o DR de um possível reconhecimento da IG; e (iii) caracterizar limites e potencialidades sinalizados pela iniciativa em curso.

Metodologicamente se trata de pesquisa analítica e descritiva baseada em estudo de caso de natureza exploratória que busca se inscrever no conjunto de esforços pelo monitoramento reflexivo da relação entre desenvolvimento e região (MATTEDI, 2015) no M édio Vale do Itajaí - SC (Figura 1). Como instrumento de coleta de dados foram realizadas entrevistas semiestruturadas com gestores de micro cervejarias artesanais da região e atores públicos e privados envolvidos diretamente nas discussões. Além destas fontes primárias o estudo fundamentou-se em fontes consubstanciadas pelos documentos produzidos nas reuniões de trabalho realizadas até o presente.

Figura 1 - Localização geográfica de Santa Catarina e do M édio Vale do Itajaí
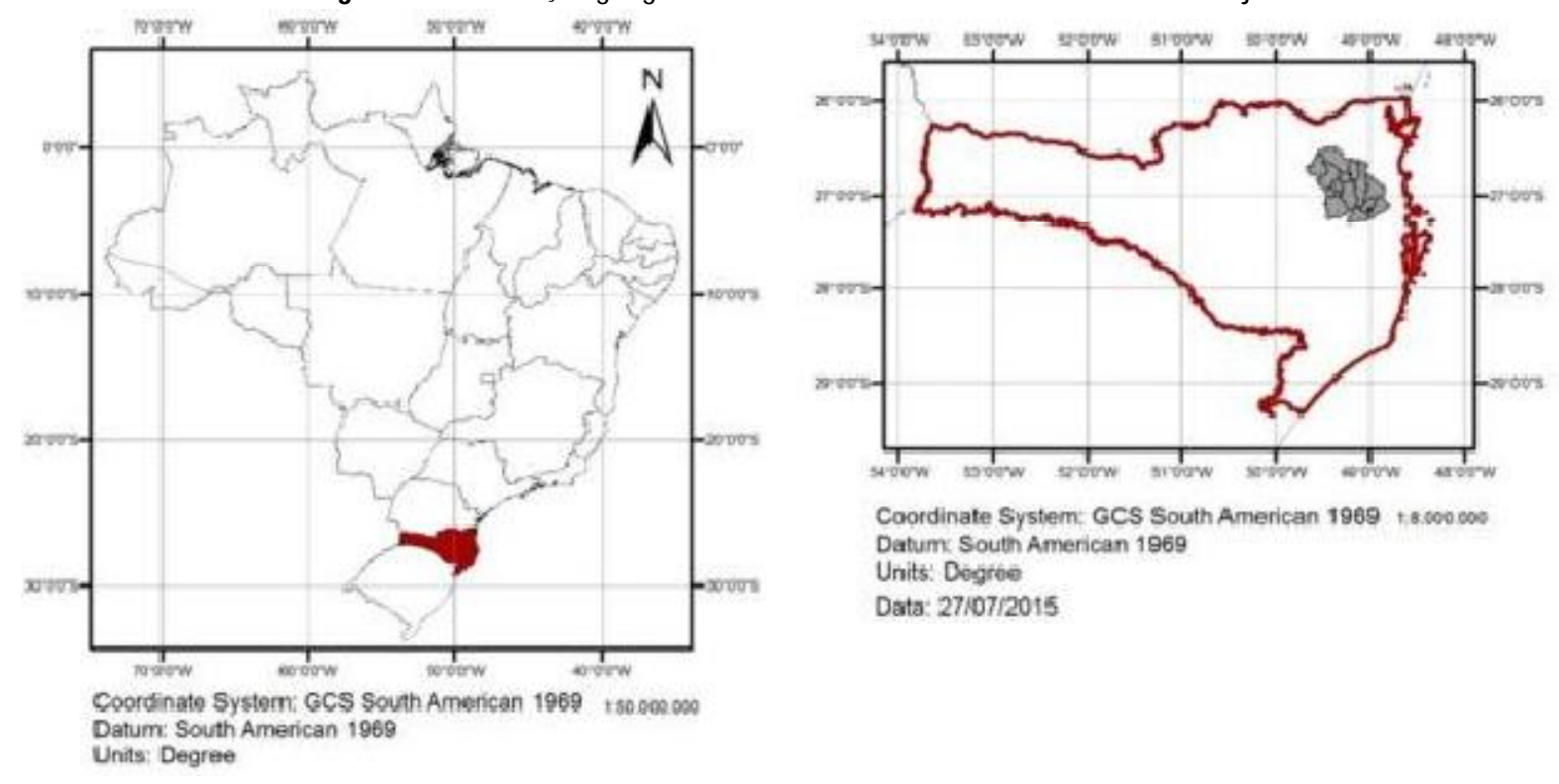

Caordinate System: GCS South American $1909+8.000000$ Datum South American 1969

Units. Dogroe

Data: $27107 / 2015$

\section{DESENVOLVIMENTO REGIONAL: UMA BREVE ABORDAGEM}

Conceitualmente desenvolvimento regional pode ser entendido como processo de desenvolvimento socialmente equitativo e ecologicamente prudente, apoiado na democratização em todas as escalas, participação ativa da cidadania na definição de seu paradigma societário, na completa soberania dos sujeitos na escolha do seu futuro (SOUZA e THEIS, 2009).

Além da questão social e ecológica apontada por Souza e Theis (2009), Siedenberg (2006) inclui e destaca a importância da variável econômica. 0 desenvolvimento regi- 
onal associa-se a mudanças sociais e econômicas que ocorrem em determinado espaço destacando também a inter-relação destas variáveis com outros elementos e estruturas presentes na região. Nesta mesma direção, Becker (2001) reforça que é necessário entender desenvolvimento regional como processo de transformações econômicas, sociais e políticas, cuja dinâmica é imprimida "de dentro e por iniciativa própria" dos agentes locais.

Sob a perspectiva econômica pode-se afirmar que as principais teorias do desenvolvimento regional sofreram transformações ao longo do tempo acompanhando mudanças estruturais da economia. Essas transformações podem ser sintetizadas em pelo menos três períodos, formando três grupos distintos de teorias:

0 primeiro grupo é composto pelas teorias tradicionais da localização industrial. A preocupação básica era definir modelos de localização da produção de forma a minimizar custos dos transportes. Estas teorias defendidas por autores como Von Thünen, Weber, Cristaller, Lösch e Isard eram teorias estáticas e se limitavam a quantificar custos e lucros na determinação da localização ótima da firma em determinada região (FOCHEZATTO, 2010).

As teorias do segundo grupo enfatizavam interdependências setoriais como fator de localização das firmas e desenvolvimento da região. Em relação ao primeiro grupo, estas teorias incorporavam a ideia de economias externas, mecanismos dinâmicos de auto reforço endógeno. Passavam a olhar a região em seu conjunto, a estrutura produtiva, com suas interligações comerciais e tecnológicas, indo além da preocupação com localização individual das firmas. No grupo, três teorias principais se destacavam: Pólos de crescimento de Perroux, Causação Circular Cumulativa de Myrdal e Teoria dos Efeitos de Encadeamento para Trás e para Frente de Hirschman (FOCHEZATTO, 2010).

Neste segundo grupo, um particular destaque é dado à Teoria dos Pólos de Crescimento, de François Perroux, desenvolvida em 1995. Perroux observou a concentração industrial na França que ocorria em torno de Paris e da Alemanha que ocorria ao longo do Vale da Ruhr. A teoria defendia que pólos industriais de crescimento surgem em torno de aglomerações urbanas importantes, ao longo de grandes fontes de matérias primas, em locais de passagens de fluxos comerciais significativos e em torno de uma grande área agrícola dependente (SOUZA, 2005).

Por fim o terceiro grupo de teorias apresenta duas abordagens distintas, embora ambos incorporem externalidades dinâmicas marshallianas. Por um lado temos autores como Krugman que busca explicar o fenômeno da localização industrial a partir da concentração do mercado de trabalho, oferta de insumos especializados e intercâmbio tecnológico. Por outro lado temos os autores evolucionistas e institucionalistas representados principalmente por Becattini e Storper que, embora também incorporem em seus modelos, economias marshalianas, diferentemente dos autores da primeira abordagem, atribuem papel importante aos agentes locais na organização dos fatores e coordenação do processo cumulativo. Em Krugman o processo cumula- 
tivo passa principalmente pelo sistema de preços e mercado, enquanto, para evolucionistas e institucionalistas, passa principalmente pela interação e coordenação entre agentes (FOCHEZATTO, 2010).

Nos anos 1950 e 1960, grande parte dos estudos se debruçava sobre o crescimento urbano e regional, ou por outras palavras, sobre o desenvolvimento regional. Identificou-se que crescimento econômico não se verifica em toda parte simultaneamente, é pontual e dinâmico e difunde-se em função da estrutura espacial e industrial da região e da armadura urbana (BENKO, 1999).

Ao se perguntar quais fatores determinam o desenvolvimento regional, Cardoso e Ribeiro (2002), afirmam que por muito tempo foi ponto assente na teoria econômica que investimentos em capital físico e humano, assim como em inovação tecnológica, eram principais fatores de expansão econômica de determinada região. Essa abordagem deixava de lado fatores endógenos como: culturais, psicológicos, sociais e ambientais que contribuem de forma decisiva para dinâmica empresarial e incremento da riqueza, não só física, mas também humana, de um território. 0 desenvolvimento regional dependerá não só do incremento de agregados econômicos mas também de fatores outros que determinam e motivam os agentes econômicos locais e enraízam socioambientalmente os empreendimentos.

A dimensão econômica é ainda reforçada por Boisier (1996), ao considerar que o desenvolvimento de uma região pressupõe existência de um processo de crescimento econômico, que pode caracterizar-se pelos seguintes atributos simultaneamente: (i) crescente processo de autonomia regional de decisão, ou seja, a região definindo seu próprio estilo de desenvolvimento, utilizando para isso os instrumentos de política necessários; (ii) crescente capacidade regional para apropriar-se de, pelo menos, parte do excedente econômico ali gerado a fim de reinvesti-lo na própria região, diversificando assim sua base econômica e oferecendo sustentação de longo prazo ao seu crescimento; (iii) crescente movimento de inclusão social e de participação da população nas decisões de competência da região; (iv) crescente processo de conscientização e mobilização social em torno da proteção ambiental e de manejo racional dos recursos naturais da região; e (v) crescente auto-percepção coletiva de "pertencimento" regional, ou seja, de identificação da população com sua região;

Desta forma, para além da lei da fatalidade e dos determinismos históricos e econômicos compreende-se que regiões e lugares, a partir de suas especificidades e potencialidades, podem encontrar formas de transformação de suas realidades, em busca de melhoria da qualidade de vida, a partir dos processos globais (CALDAS, 2003). Nesta mesma direção Aydalot (1985 p.109) também defende a relação entre recursos locais e desenvolvimento ao afirmar que "é no cenário local, por meio da valorização dos recursos locais e com a participação da população, que o desenvolvimento poderá realmente responder às necessidades da população". E é no cenário local e territorial que se vislumbra a experiência de Indicação Geográfica analisada neste trabalho, doravante contextualizada. 


\section{A PRODUÇÃO DE CERVEJA ARTESANAL EM SANTA CATARINA E NA REGIÃO DE BLUMENAU (SC)}

O Estado de Santa Catarina, no sul do Brasil, desempenha papel importante no segmento de chope e cerveja artesanal por se favorecer em relação à existência de cidades com forte presença de descendência europeia ${ }^{3}$. Além disso, o Estado possui um circuito de festas e eventos ${ }^{4}$, principalmente em outubro, que funciona como uma espécie de vitrine para projetar cervejarias artesanais do Estado em nível nacional (CUNHA, 2011).

A Associação das Cervejarias Artesanais de Santa Catarina (ACASC) é a principal entidade que apoia as organizações. Conta com 12 associadas, mas estima que o estado possui cerca de cinquenta micro cervejarias artesanais em atividade. Como resultado de uma reinvindicação da ACASC, desde 2009, as cervejarias artesanais contam com uma redução na carga tributária estadual através da Lei ํㅡ 14.961/20095 que concede um crédito presumido equivalente a $13 \%$ do valor utilizado para o cálculo do ICMS (Imposto sobre operações relativas à circulação de mercadorias e sobre prestações de serviços de transporte interestadual, intermunicipal e de comunicação).

Outra entidade que desempenha papel importante, principalmente na manutenção da cultura da cerveja artesanal no Estado, é a Associação dos Cervejeiros Artesanais de Santa Catarina (ACerVa Catarinense). A associação desempenha várias atividades relacionadas a cerveja artesanal e suas ações tem capilaridade em todas as regiões do Estado, graças a suas diretorias regionais.

Neste contexto de relação entre cerveja artesanal e território a região de Blumenau (SC) se destaca diante das outras regiões do Estado ${ }^{6}$. Sua relação com a produção de cerveja artesanal é histórica e remonta a colonização pelos imigrantes alemães. Silva (1960) lembra que esses imigrantes trouxeram na mala tradições e cultura do país de origem, onde a produção e consumo de cerveja era mais antiga. Foi em 1858, com a chegada de Heinrich Hosang, que se iniciou a fabricação de cerveja ${ }^{7}$ na região. Sua fá-

3 Para Lombardo $(2008$, p.78) Cerveja é algo levado a sério em Santa Catarina há mais de 150 anos. Imigrantes alemães, suíços e austríacos, em especial aqueles estabelecidos no Vale do Itajaí, trouxeram na bagagem a tradição cervejeira da velha Europa e ergueram várias pequenas fábricas, conferindo grande importância econômica e cultural ao setor até a primeira metade do século passado.

4 Neste sentido é possível destacar dois exemplos em Blumenau: o importante papel da Ocktoberfest, que oportuniza a comercialização da cerveja artesanal em um dos seus pavilhões e, mais recentemente, o Festival Nacional da Cerveja que vem consolidando-se como o principal evento da cerveja no Brasil.

5 A lei pode ser acessada em http://www.legisweb.com.br/legislacao/?id=163243

6 Assim como a região de Blumenau (SC), a região de Florianópolis (SC) também vem se tornando um polo cervejeiro. Atualmente a região possui sete cervejarias artesanais em atividade: Faixa Preta e Badenia em Santo Amaro da Imperatriz; Jester em Águas Mornas; Cervejaria da Ilha em Florianópolis; The Liffey (Brewpub) em Palhoça, Cerveja Sambaqui e Cervejaria da Lagoa (são marcas de Florianópolis mas a cerveja é produzida em outras regiões).

7 Em pesquisa realizada no Centro Histórico de Blumenau, constatou-se um livro de registros de vendas de cervejas entre os anos de 1880 e 1881. Assim, verifica-se, neste livro, que os moradores consumiam em 
brica prosperou acompanhando o crescimento do consumo da bebida que preparava e que era preferida no comércio local. Hosang esteve à frente de sua fábrica até 1888, quando faleceu com 60 anos de idade. Mesmo com sua morte, a viúva, auxiliada por seu filho Otto, deu continuidade na fabricação de cerveja. A partir da iniciativa de Hosang, anos mais tarde, vários fabricantes de cerveja surgiram em Blumenau.

Outra cervejaria de destaque foi a Feldmann que iniciou atividades em $1898 \mathrm{com}$ uma pequena produção caseira, de fundo de quintal. Nesta época eram muitos os desafios enfrentados. 0 primeiro, conseguir matéria prima para a produção. 0 lúpulo era uma flor importada da Rússia e o maquinário para produzir as marcas Victoria e Bock era totalmente manual. Outro desafio era a entrega dos produtos. Em 1959, a Cervejaria Feldmann se limitou a produção de licores e gasosas. A melhoria nos acessos à cidade contribuiu para a entrada de grandes marcas de cerveja e a cervejaria da família perdeu competitividade, encerrando suas atividades definitivamente em 1978 (FREESE, 2008).

A Cervejaria de Otto Jennrich surgiu no bairro Itoupava Seca em 1891 e rapidamente tornou-se ponto de encontro e reuniões. Tinha decoração que imitava uma tradicional "bierstube" de M ünchen. Fabricavam-se três tipos de cerveja: Estrela, Polar e Kulmbach. Anos após a sua fundação, a fábrica foi incorporada a Antártica Paulista (FREESE, 2008).

Além de Blumenau (SC), o vizinho município de Timbó (SC) também movimentava a produção de cerveja artesanal. No município se destacou a Cervejaria Brandes entre os anos de 1903 a 1938, quando encerrou suas atividades em razão da forte concorrência imposta pelas grandes cervejarias nacionais. Em Indaial surgia a Cervejaria Indaial fundada por Walter Alberto Pershun que chegou a trabalhar na cervejaria de Otto Jennrich, em Blumenau (SC). A cervejaria foi inaugurada em 1928 e produzia dois tipos de cerveja: clara e escura. Depois de algum tempo começou a fabricar também as gasosas. A cervejaria continuou suas atividades até a década de sessenta (FREESE, 2008).

A notoriedade de Blumenau (SC) como polo produtor de cerveja é reconhecida nacional e internacionalmente, ao ponto de estar tramitando na Câmara dos Deputados um projeto de lei que atribui a Blumenau (SC) o título de "Capital Nacional da Cerveja". 0 autor do projeto elencou algumas justificativas para o pedido: (i) mesmo antes de se tornar município, Blumenau (SC) produzia cerveja através dos imigrantes; (ii) nos anos oitenta a cidade criou a oktoberfest, conhecida como a maior festa de cerveja do país; e (iii) atualmente o município é conhecido como polo cervejeiro, devido a ampliação de sua produção artesanal influenciando, inclusive, a produção de cerveja artesanal em vários municípios vizinhos. A relatora do projeto na Comissão de Cultura sugeriu sua aprovação destacando que a história da cerveja em Blumenau remonta sua colonização. Atualmente o município é sede do Festival Nacional da Cerve-

abundância as cervejas fabricadas por Hosang, dentre eles estavam o dono do hotel, o médico da colônia, 0 engenheiro, bem como a família de Dr. Blumenau (SILVA, 1960). 
ja e realiza o maior concurso anual de cerveja.

Nos últimos anos o segmento de chope e cerveja artesanal tem se expandido na região. Em 2015 a região de Blumenau ${ }^{8}$ contava com doze microcervejarias distribuídas espacialmente em sete municípios: Bierland, Oktobier, Belgard, Container British Beer e Wunder Bier (Blumenau); Zehn Bier (Brusque); Borck e Berghain (Timbó); Das Bier (Gaspar); Heimat (Indaial), Schornstein (Pomerode) e Kiezen Ruw (Guabiruba).

Figura 02 - Rótulos de cervejarias artesanais da região de Blumenau (SC).
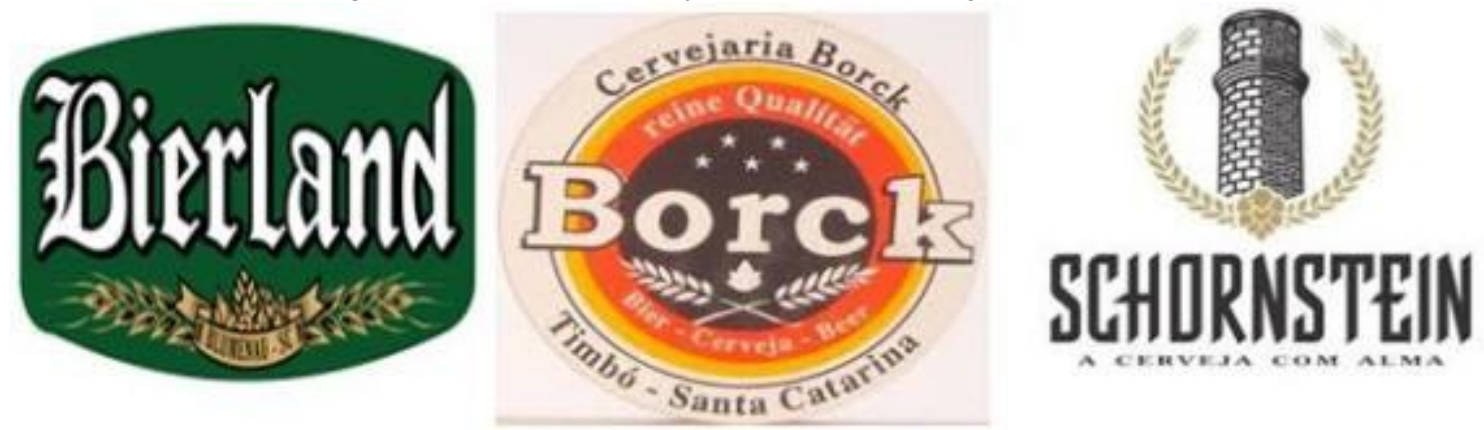

Este crescimento tem estimulado o surgimento de outros empreendimentos diretamente relacionados à cadeia de produção do segmento. Na cidade de Blumenau foi criada a primeira Escola Superior de Cerveja e M alte (ESCM) da América Latina. Também em Blumenau foi criada, em 2015, a primeira micromaltaria especial do Brasil, com capacidade inicial de produção de 5 toneladas/mês a partir da utilização de cevada produzida no Brasil e fundado o Vale do Lúpulo, especializado na importação de lúpulos.

\section{INDICAÇÃO GEOGRÁFICA PARA CHOPE E CERVEJA ARTESANAL E DESENVOLVI- MENTO REGIONAL}

Indicações Geográficas (IGs) são um instituto jurídico utilizado para identificar a origem de produtos ou serviços quando determinado local tenha se tornado conhecido por sua produção/realização ou quando determinada característica ou qualidade deste produto ou serviço possui relação com sua origem. No Brasil, o termo foi introduzido por ocasião da promulgação da Lei da Propriedade Industrial 9.279 de 14 de maio de 1996 - LPI/96 (INPI, 2016). A legislação brasileira classifica IGs em Indicação de Procedência (IP) e Denominação de Origem (DO) ${ }^{9}$.

Com a consolidação deste instituto, IGs passaram a ser entendidas também como uma possibilidade de agregação de valor a produtos ou serviços que tem característi-

8 Geograficamente entende-se como região de Blumenau, a região do M édio Vale do Itajaí.

9 De maneira objetiva a IP exige notoriedade (fama ou reputação) do local de produção dos produtos ou serviços. A DO exige comprovação de que o produto ou serviço possui qualidade ou características que se devem essencialmente ao local (meio geográfico) de origem considerando-se fatores naturais como clima, solo dentro outros fatores, e humanos como modo de fazer (BRUCH et al, 2010). 
cas próprias, relacionadas ao território ao qual estão inseridas. Essa agregação de valor pode representar aumento significativo na renda dos produtores envolvidos seja através do aumento no preço dos produtos oferecidos, no aumento do volume de vendas ou na conquista de novos mercados. Representam também a valorização de tradições locais associadas ao fortalecimento de uma identidade cultural própria. Além disso, podem fortalecer atividades complementares que surgem após o reconhecimento de produtos tradicionais. É o que o Pecqueur (2001) denomina de "cesta de bens e serviços do território". Um exemplo são as atividades relacionadas ao turismo ${ }^{10}$.

Foi a forte relação histórica entre a cerveja artesanal e a região de Blumenau (SC) que estimulou as discussões relacionadas a possibilidade de solicitar reconhecimento da IG para o segmento. Estas discussões envolveram dez micro cervejarias de oito municípios (Figura 3): Bierland, Eisenbahn e Wunder Bier (Blumenau); Zehn Bier (Brusque); Borck (Timbó); Das Bier (Gaspar); Heimat (Indaial), Schornstein (Pomerode), Königs Bier (Jaraguá do Sul) e Opa Bier (Joinville) e foram estimuladas e coordenadas pelo Núcleo de Inovação Tecnológica da Universidade Regional de Blumenau $(\mathrm{NIT/FURB})^{11}$

10 Após o reconhecimento da indicação geográfica, o Vale dos Vinhedos, cuja área envolve três municípios (Bento Gonçalves, Garibaldi e Monte Belo do Sul), estruturou propostas de roteiros pelas vinícolas (roteiro enológico, gastronômico e cultural) aumentando significativamente o fluxo de turistas na região e a venda de produtos artesanais, complementando a renda dos produtores, principalmente das pequenas vinícolas.

11 Além do NIT participaram diretamente das discussões o Serviço Brasileiro de Apoio às Micro e Pequenas Empresas (Sebrae), Ministério da Agricultura, Pecuária e Abastecimento (MAPA), Cervejarias artesanais, Universidade Federal de Santa Catarina (UFSC) e indiretamente Secretaria de Desenvolvimento Regional (SDR) de Blumenau, SDR de Timbó, Prefeituras de Blumenau, Timbó e Brusque e Empório vila germânica e ACASC. 0 NIT foi 0 ator protagonista nas discussões. Entretanto uma reestruturação interna ocorrida na FURB acabou desativando o NIT e com isso as discussões em torno do reconhecimento da IG foram paralisadas e não retornaram até o momento. As SDR foram recentemente transformadas em Agências de Desenvolvimento Regional (ADR) pelo governo de Santa Catarina. 
Figura 3: Localização das cervejarias artesanais envolvidas nas discussões do reconhecimento da IG de Blumenau e região.

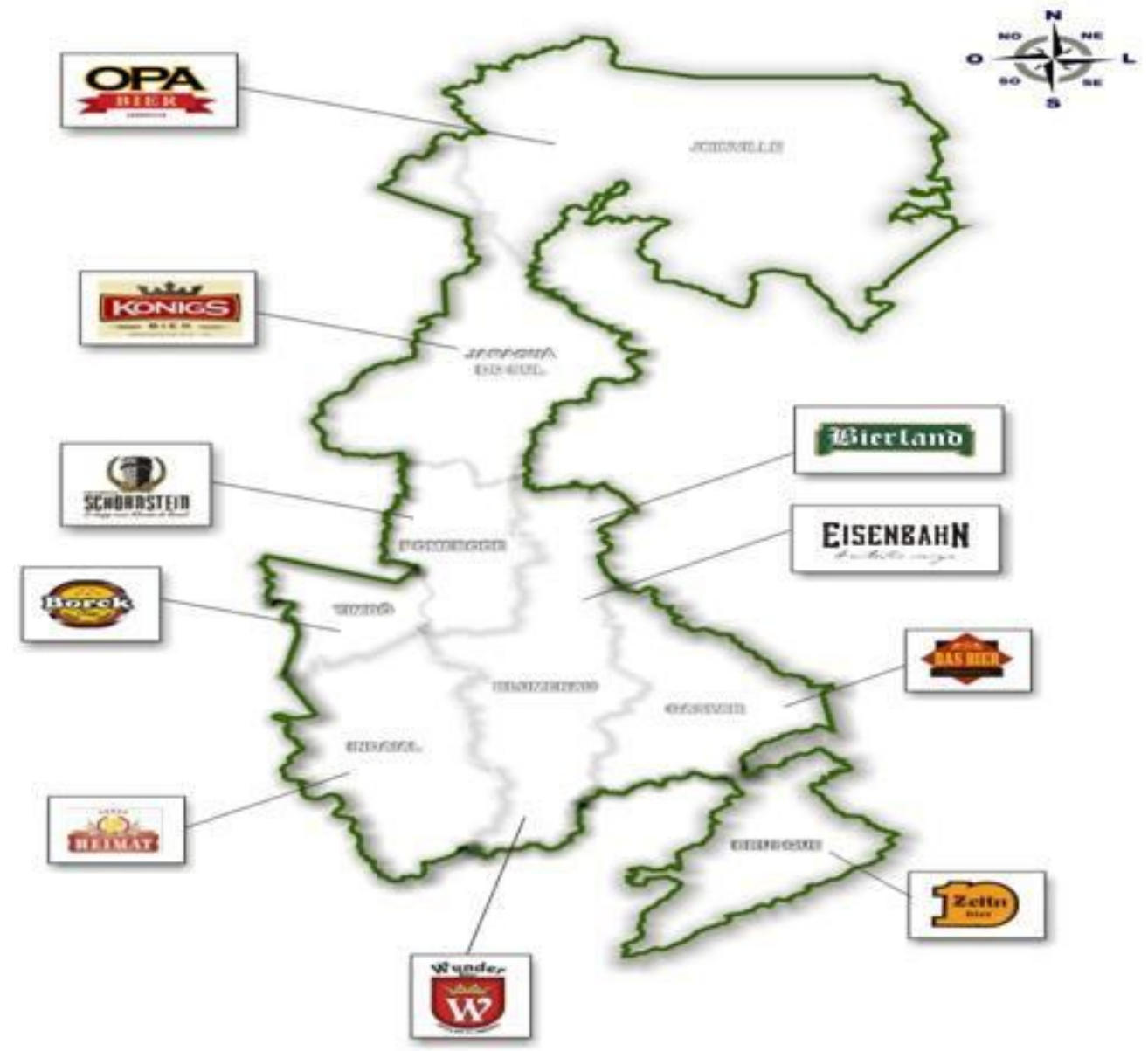

Fonte: Núcleo de Inovação Tecnológica / FURB.

Trata-se de um tema que, mesmo embrionário, estimula discussões relacionadas às vantagens que este reconhecimento de IG pode oferecer aos produtos, ao desenvolvimento regional e os desafios que precisam ser enfrentados para que isso se concretize.

\subsection{Contribuições do reconhecimento da IG para micro cervejeiros e região}

Do ponto de vista das potencialidades da iniciativa há condições para obtenção do reconhecimento da IG. A região possui notoriedade na produção de chope e cerveja artesanal de qualidade que pode ser comprovada pelas origens históricas e culturais presentes na fabricação da cerveja desde sua colonização ${ }^{12}$ (PELLIN, M ANTOVANELLI Jr, 2015). Neste sentido, o reconhecimento pode oferecer contribuições importantes para o segmento e para o desenvolvimento regional.

Para os empresários do setor, o reconhecimento da IG pode oferecer vantagens importantes, sobretudo na dimensão econômica. Em primeiro lugar, o reconhecimento

12 A notoriedade é condição indispensável para reconhecimento de IG na modalidade Indicação de Procedência (IP). 
pode ser fundamental para micro cervejeiros diferenciarem seus produtos em um mercado cada dia mais competitivo. Em função da popularização da cerveja artesanal no país, a competitividade do setor aumentou consideravelmente nos últimos anos, inclusive em nível estadual. Portanto, o reconhecimento facilitaria a expansão dos mercados. A região e os produtos se tornariam mais conhecidos o que contribuiria para sua inserção em grandes centros de consumo no país, conquistando mercados exigentes. Em segundo lugar, mas não menos importante, o reconhecimento poderia fortalecer a cooperação entre micro cervejeiros da região. Em função do reconhecimento ser solicitado coletivamente haveria estimulo ao fortalecimento de vínculos entre os empresários, e destes com atores externos, estimulando o capital social na região.

Em relação a região é preciso considerar algumas especificidades do segmento. De acordo com França (2010) micro cervejarias artesanais da região não impactam significativamente a economia, principalmente quando se analisa a geração de emprego e renda. A maioria delas tem um faturamento relativo a microempresas, gerando pouquíssimos empregos quando comparados tacitamente ao que é percebido em empresas de outros setores.

Entretanto podem contribuir para o desenvolvimento regional através do fortalecimento da cadeia produtiva do setor e da expansão da atividade turística. Em relação a cadeia produtiva houve considerável aumento no número de empreendimentos relacionados ao setor nos últimos anos. Atualmente a região conta com a Escola Superior de Cerveja e Malte (ESCM), primeira escola do gênero na América latina, a primeira micromalteria especial do Brasil e várias empresas especializadas na importação de matéria prima. Além disso, está ocorrendo um crescimento no número de micro cervejarias artesanais instaladas na região de Blumenau (SC). Atualmente são doze unidades em atividade. 0 turismo vem se beneficiando desse reconhecimento. Haverá inevitavelmente um fortalecimento ainda maior da imagem da região como produtora de cerveja artesanal de qualidade o que contribuirá, por exemplo, para a consolidação de uma Rota de Cerveja Artesanal ${ }^{13}$ na região.

Em relação a criação de uma rota está em fase de implementação o "Projeto Vale da Cerveja ${ }^{14 "}$ organizado pelo trade turístico de Blumenau e região. Seis entidades lideram esse projeto: Associação das Cervejarias Artesanais de Santa Catarina, Blumenau e Vale Europeu Convention e Visitors Bureau, Sindicato dos Hotéis, Bares, Restaurantes e Similares, Escola Superior Cerveja e Malte, Sindilojas e Secretaria de Turismo de Blumenau, que contam com a assessoria do Senac, responsável pela metodologia de implantação. 0 principal produto deste projeto é a "Rota Turística Vale da Cerveja -SC" que envolve doze micro cervejarias artesanais de seis municípios: Blumenau, Brusque, Gaspar, Ibirama, Pomerode e Timbó e foi lançada oficialmente em

13 A criação de rotas constitui-se em uma importante estratégia para o fortalecimento do turismo em uma determinada região. Um exemplo disso são as rotas de enoturismo na Europa em particular na França, Espanha, Itália e Portugal.

140 projeto pode ser acompanhado no site http://www.valedacerveja.com/

PRACS: Revista Eletrônica de Humanidades do Curso de Ciências Sociais da UNIFAP 
março de 2016.

Outra contribuição é a expansão de eventos relacionados direta ou indiretamente com produção de cerveja artesanal, além do fortalecimento daqueles eventos já amplamente consolidados.

\subsection{Desafios e limites sinalizados pela experiência em curso}

Destas potencialidades desdobram-se, entre os limites o fato de que as discussões identificaram problemas que podem comprometer ou retardar sua obtenção. Na opinião de Pellin e Mantovaneli Jr (2015) além de encontrar outro ator capaz de conduzir a iniciativa com a mesma proatividade do NIT/FURB, será preciso resolver ou mitigar pelo menos três conflitos ${ }^{15}$ que colocam em risco a vitalidade da discussão:

0 primeiro conflito relaciona-se à constituição da organização que representaria 0 interesse dos atores na solicitação da IG. Alguns membros defendem que a ACASC poderia representar as cervejarias interessadas e 0 argumento é que a associação já existe legalmente. Outros membros defendem a necessidade da criação de uma associação específica formada apenas por cervejarias e demais entidades interessadas na IG. Questão relacionada ao sistema de poder subjacente a esta associação. Sua base empresarial consolidada e menos sujeita a externalidades.

0 segundo ponto conflitante tem relação com a delimitação geográfica. Alguns membros defendem que a IG seja delimitada apenas por cervejarias localizadas no município de Blumenau e municípios vizinhos. Outros membros defendem a participação de municípios de regiões vizinhas como Jaraguá do Sul e Joinville que também tem tradição na produção de cerveja artesanal.

0 terceiro ponto em conflito refere-se a questões financeiras. A preocupação foi verificada desde a primeira reunião. O NIT tentou mobilizar recursos em entidades de fomento como a Fundação de Amparo à Pesquisa e Inovação do Estado de Santa Catarina (FAPESC) e o Conselho Nacional de Desenvolvimento Científico e Tecnológico (CNPQ) para iniciar os trabalhos de reconhecimento. No entanto os projetos não foram aprovados. Com o aprofundamento das discussões entre os atores interessados a preocupação financeira aprofundou-se. Os cervejeiros demonstraram interesse na IG, mas não em aportar financeiramente o projeto. Para os cervejeiros o projeto deveria ser subsidiado por organismos públicos.

Ao analisar estes três pontos conflitantes é possível afirmar que a tensão entre 0 interesse individual e coletivo se constitui em um desafio significativo na IG da Cerveja em Blumenau (SC) e região, determinando seus limites e potencialidades.

15 No que tange à dimensão conflituosa presente neste tipo de iniciativa, nos termos em que vêm sendo fomentadas pelo MAPA as políticas de IG no Brasil há preocupações em que tais iniciativas contribuam para uma abordagem de desenvolvimento territorial sustentável. Sob tal premissa a mitigação ou resolução de conflitos é sempre problematizada pela via da sustentabilidade econômica. 0 que implica em uma lógica mais cooperativa e socialmente enraizada, na direção do que nos coloca a clássica obra de Polanyi (2012) e no sentido político do que nos apresenta o debate sobre governança em M antovaneli Jr. e Sampaio (2007).

PRACS: Revista Eletrônica de Humanidades do Curso de Ciências Sociais da UNIFAP 


\section{CONSIDERAÇÕES FINAIS}

A produção de cerveja artesanal tem se popularizado e expandido em todo o Brasil. A região de Blumenau (SC) foi um dos primeiros polos brasileiros de produção de cerveja artesanal e ainda possuí algumas das mais tradicionais micro cervejarias em atividade no país. Trata-se de um dos produtos mais conhecidos na região e, em função disso, em 2010 iniciaram discussões relacionadas a solicitação do reconhecimento de Indicação Geográfica (IG) para os produtos.

De maneira geral as IGs podem ser entendidas como instrumento que possibilita a obtenção de vantagens, sobretudo econômicas, para os produtores e região. Podem representar também uma forma de manter e fortalecer tradições locais destacando e evidenciando a identidade local.

Neste contexto entende-se que o reconhecimento da IG para o segmento do chope e cerveja artesanal da região de Blumenau (SC) pode constituir-se em uma estratégia interessante para o desenvolvimento regional. Na dimensão econômica o reconhecimento da IG diferenciaria o produto, aumentando sua competitividade e a possibilidade de se inserir em grandes mercados consumidores.

Na dimensão social, haveria o fortalecimento do capital social a partir do momento em que os micro cervejeiros passariam a desenvolver ações mais cooperadas em função de que a IG precisa ser solicitada e gerenciada coletivamente. 0 que, acredita-se, geraria positivos impactos políticos na gestão das políticas econômicas potencializadas por este segmento.

Sob o aspecto territorial, o reconhecimento consolidaria a região de Blumenau (SC) como a região das cervejas artesanais no Brasil, além de fortalecer atividades complementares como o turismo através da criação de uma Rota da Cerveja Artesanal e do fortalecimento de eventos relacionados direta ou indiretamente com o setor.

Entretanto para isso, conflitos precisam ser superados. Merece destaque a divergência de interesses entre os envolvidos, alguns de ordem financeira, outros de ordem política na constituição da associação que representará os envolvidos na busca da IG, bem como de ordem político-mercantil, típicos de empresas habituadas mais em competir do que em cooperar e que precisarão discutir a qualidade de seus produtos e suas premissas na produção daquilo que será objeto da IG.

Por fim, desta experiência depreende-se que 0 instituto das IGs guarda potencialidades bastante virtuosas ao desenvolvimento em suas múltiplas dimensionalidades. Desde que a conflitividade típica dos interesses presentes em situações de grande potencialidade, não seja sublimada por hegemonias pouco simpáticas à dialética da cooperação competitiva, necessária na promoção do desenvolvimento territorial em bases democráticas e economicamente sustentável, portanto socialmente enraizado. 


\section{REFERÊNCIAS}

AYDALOT, Philippe. Économie régionale et urbaine. Paris: Économica, 1985

BECKER, Bertha. Revisão das políticas de ocupação da Amazônia: é possível identificar modelos para projetar cenários? Parcerias Estratégicas. Brasília, n.12, p. 135-159, set. 2001.

BENKO, Georges. A Ciência Regional. Celta Editora, Oeiras.1999.

BOISIER, Sergio. M odernidad y territorio. Santiago de Chile: ILPES, 1996.

BRUCH, Kelly Lissandra; VITROLLES, Delphine; LOCATELLI, Liliana. Estudo de Caso: IP Vale dos Vinhedos, IP Paraty e IP Vale do Submédio São Francisco. In: CERDAN, Clarie Marie; BRUCH, Kelly Lissandra; SILVA, Aparecido Lima da. Curso de Propriedade Intelectual e Inovação no Agronegócio: Módulo II - Indicação Geográfica. M APA. Florianópolis SEaD/UFSC/FAPEU. 2010.

CALDAS, Alcides dos Santos. As denominações de origem como unidade de planejamento, desenvolvimento local e inclusão social. Revista de Desenvolvimento Econômico. Ano V, n 08, Salvador - BA. Julho de 2003.

CARDOSO, Teresa; RIBEIRO, José Cadima. Economia para o homem e desenvolvimento regional: contribuição para um pensamento e uma política regional alternativos. In. BECKER, D. F; BANDEIRA, P.S (Org). Respostas regionais aos desafios da globalização. Santa Cruz do Sul, EDUNISC, 2002.

CUNHA, Tiago Vargas da. Competitividade e segmentação na indústria cervejeira: uma análise da competitividade de micro cervejarias catarinenses. Monografia (Graduação em Ciências Econômicas) - Universidade Federal de Santa Catarina. Florianópolis - SC, 2011.

FOCHEZATTO, Adelar. Desenvolvimento regional: novas abordagens para novos paradigmas produtivos. In: CONCEIÇÃO, Octávio A. C.; et. al. (Org.). 0 ambiente regional. Porto Alegre: FEE, 2010. (Três décadas de economia gaúcha, 1 ).

FRANÇA, Eduardo. Formação e desenvolvimento das redes de cervejarias artesanais no Vale do Itajaí. Dissertação (M estrado em Desenvolvimento Regional) - Universidade Regional de Blumenau (FURB). Blumenau, 2010.

FREESE, Soila. Ein Prosit Blumenau: A história da Cerveja em Blumenau. Blumenau. Editora do autor, 2008.

INPI. Instituto Nacional de Propriedade Industrial. Indicações Geográficas Reconhecidas. Disponível em < http://www.inpi.gov.br/menu-servicos/indicacao-geografica>. Acesso em: jan. 2016.

LOM BARDO, João Alexandre. Santa Catarina à mesa: a revolução das uvas e do vinho e o renascimento das cervejarias no estado. 1 Edição. Editora Expressão, Florianópolis (SC), 2008.

M ANTOVANELI JR. Oklinger; SAM PAIO, Carlos Alberto Cioce. Sustentabilidade política e administrativa: contribuições para a reformulação da agenda para o ecodesenvolvimento. Revista de Gestão Social e Ambiental. Maio/Agosto 2007, v.1, n. 2 p.3-21, 
Salvador. 2007.

M ATTEDI, Marcos Antônio. Pensando com o desenvolvimento regional: subsídios para um programa forte em desenvolvimento regional. Revista Brasileira de Desenvolvimento Regional. Blumenau, v. 2, n. 2, p. 059-105, jun. 2015. ISSN 2317-5443. Disponível em: বttp://proxy.furb.br/ojs/index.php/rbdr/article/view/4807/2968>. Acesso em: 04 jul 2016. doi:http:// dx.doi.org/10.7867/2317-5443.2014v2n2p059-105.

PECQUEUR, Bernard. Qualité e développement territorial: I' hyphotèse du pannier de biens et de services territorialisés. Paris. Economie Rurale, n. 261, 2001.

PELLIN, Valdinho; MANTOVANELI Jr. Oklinger. Desenvolvimento e novas territorialidades: a indicação geográfica da cerveja artesanal de Blumenau e região. In: VIEIRA, Adriana Carvalho Pinto; BRUCH, Kelly Lissandra (Org) - Indicação Geográfica, Signos Distintivos e Desenvolvimento. Editora IBPI, São Paulo -SP, 2015.

POLANYI, Karl. A economia enraizada na sociedade. In: mem e ensaios correlatos. Rio de Janeiro: Contraponto, 2012.

. A subsistência do ho-

SILVA, José Ferreira. Cervejarias de Blumenau. Blumenau em Cadernos. Blumenau, Tomo III, n. 9, p. 161-170, set. 1960.

SIEDENBERG, Dieter Rugard. Desenvolvimento Regional. In: SIEDENBERG Dieter Rugard (org). Dicionário desenvolvimento regional. Santa Cruz do Sul, EDUNISC, 2006. $168 \mathrm{p}$.

SOUZA, Cristiane Mansur de Moraes; THEIS, Ivo Marcos; Desenvolvimento Regional: abordagens contemporâneas. Blumenau. Edifurb. 2009.

SOUZA, Neli de Jesus. Desenvolvimento econômico. 5ạ Edição. São Paulo: Atlas, 2005. THEIS, Ivo Marcos. Desenvolvimento e Território: Questões teóricas, evidências empíricas - breve introdução. In: THEIS, I. M (Org). Desenvolvimento e Território: Questões teóricas, evidências empíricas. Santa Cruz do Sul. EDUNISC, 2008.

Artigo recebido em 04 de julho de 2016.

Aprovado em 13 de outubro de 2016. 